\title{
Awareness and Attitude to Correct English Pronunciation at Higher Secondary Level in Bangladesh
}

\author{
Md. Khurshedul Alam ${ }^{1}$, K.M. Jubair Uddin ${ }^{2 *}$ \\ ${ }^{1}$ Lecturer in English, Faculty of Science, University of Chittagong, Bangladesh \\ ${ }^{2}$ Lecturer in English, Faculty of Biological Science, University of Chittagong, Bangladesh
}

*Corresponding Author: K.M. Jubair Uddin, Lecturer in English, Faculty of Biological Science, University of Chittagong, Bangladesh

\begin{abstract}
Language dies between two lips because of faulty pronunciation. English is famous for its world wide use but notorious for its pronunciation. In the new era of 21 st century, awareness of correct English pronunciation is essentially essential in the context of Bangladesh. English pronunciation seems to enjoy little or no room in the practice and policy in Bangladesh. Nowadays anyone unable to speak correct English faces enormous social, personal, and economic limitations in today's fast, complex, information-flooded world. This study, therefore, aims at exploring the levels of awareness and attitude to correct English pronunciation of higher secondary learners of Bangladesh and to show whether the learners' attitude to pronunciation skill is positive or negative and whether their awareness is very low or high. On top of that, the present study centres on the point to find out whether students at college level know correct pronunciation and whether they encounter problems in English pronunciation. The study also aims to reveal whether the learners are conscious or not of the pronunciation errors they make with regard to the utterance of certain sounds and stress placement in English language. Finally, this study intends to help the learners to become aware, to make them speak correct English, to make them acceptable globally and eventually to use their positive attitude in acquiring and solving English pronunciation problems.
\end{abstract}

Keywords: Correct Pronunciation, Awareness, Attitude, Standard Pronunciation, IPA Symbols and Native Sound

\section{INTRODUCTION}

The curse of unawareness of correct English pronunciation is usually common among the higher secondary learners of Bangladesh. There is no doubt about that wrong pronunciation is certainly enough to spoil the probability of higher secondary learners of Bangladesh. The learners will misunderstand and will be misunderstood by others for their mispronunciation. The speaker of wrong pronunciation in English is like a person with dirty clothes and this scenario is deeply rooted at higher secondary level in Bangladesh. It is needless to say that pronunciation is a set of habits of producing sounds to overcome the bias of the first language but this set of habit is hardly seen among the higher secondary learners for English. The learners do not know that the habit of producing a sound correctly is acquired by repeating it over and over again and by being corrected when it is pronounced wrongly. Therefore, the higher secondary learners should know that learning to pronounce a foreign/second language means building up new pronunciation habits and overcoming the bias of the first language (Cook, 1996). Moreover, the learners have a common tendency to spelling pronunciation which is often considered as wrong pronunciation and the higher secondary learners are habituated to it. Regarding this, David Crystal, (2002) says that we all learn to speak before we learn to write. We also need to remember that pronunciation patterns have changed radically since the days when the spelling system was laid down. English spelling hasn't been a good guide to pronunciation for hundreds of years.

Bangladesh is basically a monolingual country. But it is true that, English is dominating the country and at the higher secondary level in Bangladesh, sufficient attention is paid to grammar and vocabulary in English. Though pronunciation is another major sub-skill to be acquired when learning English language, it is, unfortunately, often forgotten or neglected at least up to the higher secondary level in Bangladesh. This might be due to the faulty educational system of Bangladesh, lack of pronunciation knowledge of a considerable number of teachers, unawareness of a large number of students who are not aware of the importance of some phonetic and phonological aspects of English. 
As a result, a number of students at higher secondary level cannot speak English with correct English pronunciation. So, these educated but faulty FL/SL English speakers of higher secondary level of Bangladesh are condemned for incorrect pronunciation by the listeners who have sufficient knowledge of authentic pronunciation in English. Moreover, a large number of students at higher secondary level face difficult situations in facing international examinations, getting a good job, going to abroad for higher studies and so on.

\subsection{Purpose of the Study}

The purpose of the study is to investigate the present level of awareness and attitude to correct English pronunciation of the higher secondary learners in Bangladesh. It intends to increase the positive attitude and to apply it for acquiring correct English pronunciation as well as to decrease the hugely used wrong pronunciation of English by the higher secondary learners in Bangladesh. The study also wishes to dig up the blunt enthusiasm of the learners to learn correct English and to understand and to be understood globally as a good speaker of English. On top of that, the study expects to make them aware not to be condemned or neglected by others as wrong speakers in English and to make them practice correct pronunciation to pave the way of getting good jobs in home and abroad.

\subsection{Research Questions}

- Are the higher secondary learners of Bangladesh conscious of correct English pronunciation?

- To what extent the learners are familiar with correct English pronunciation?

- What are the reasons behind their unawareness of correct pronunciation?

- Do the learners know some basic components of English pronunciation?

- What is the learners' attitude to learn English pronunciation?

\subsection{Significance of the Study}

The present study attempts to bring out the suicidal ignorance of the higher secondary learners about correct English pronunciation and to persuade them to uproot it. The study investigates whether the learners give importance equally to English vocabulary, grammar as well as correct pronunciation. This study measures specially the present level of higher secondary learners' consciousness and stance to correct English pronunciation and to keep them from faulty pronunciation that obviously hampers communicative competence and performance which are leading the learners to face some unwelcome situations in home and abroad. The study pays special attention to correct English pronunciation that allows the learners to interact with native speakers spontaneously to build up proper rapport and on the other hand, it focuses on poor pronunciation that hampers learners to their deserved social, academic and work advancement. The study may help to pave the way of the higher secondary learners who go to abroad for higher study or for other purposes or who enter into tertiary level in Bangladesh and have to be embarrassed for wrong pronunciation.

The study focuses particularly on HSC level since learning pronunciation is a lengthy process and that is why the study and practice of correct pronunciation should be started at this level to accomplish it well. There is another significance of this study that the learners at HSC level are usually enthusiastic and mature enough to make them aware of correct English pronunciation and it will make more easy acquiring correct pronunciation at tertiary level. Though some reflective studies have been carried out on the necessity of awareness and attitude toward English pronunciation in general, there seems to be hardly any empirical research done at HSC level on the topic in Bangladesh. In this regard, the present study is significant for the research community pouring sunny light on the problems. Moreover, the result of the study can serve as an input to the decisions that practitioners and material designers make to address the needs of the students for mutually intelligible pronunciation.

\subsection{Limitations of the Study}

The results of the current study must be viewed in light of some unavoidable limitations. Primarily, this study focuses only on some responses of the higher secondary students of a few colleges. Due to this limitation, the results might be different in other contexts. Further study may be done increasing data in terms of including more students. In light of this study, it is important to investigate further the cause of the students' low awareness level of correct English pronunciation, which started in their 
classroom compound. Future research is required for more evidence from more students of various colleges across the country to draw a conclusive conclusion.

\section{LITERATURE REVIEW}

Nusrat Jahan (2011) mentions that most of the teachers (60.78\%) are dissatisfied with the students' pronunciation level while they start English Language class at tertiary level. In the discussion, students also admit that they are not happy with their pronunciation level and then they commented that they did not get proficient teachers. It has been observed that students cannot overcome their shyness at tertiary level also, as some of the students admit in the discussion that they felt shy while practicing correct pronunciation or when their teachers criticized and made a correction of their pronunciation.

In a study on pronunciation accuracy of university students studying intermediate Spanish as a foreign language, Elliot (1995) found that subjects' attitude toward acquiring native or near native pronunciation, as measured by the Pronunciation Attitude Inventory (PAI), was the principal variable in relation to target language pronunciation. In other words, if the students were more concerned about their pronunciation of the target language, they tended to have better pronunciation of the target allophones (Elliot, 1995). According to Elliot (1995) students who were more concerned about their pronunciation had better pronunciation of English language. Sparks and Ganschow (1991) also state that students with motivation to learn with positive attitudes towards the target language and its speakers were more successful than students with less positive attitudes.

Rajadurai, Joanne(2001) discusses whether an 18-year-old is too late for second language pronunciation training to make a difference. In the context under investigation, more than 75 percent of the students agreed that pronunciation work had helped them, and this view is endorsed by course instructors. It appears that students and instructors agree that improvements in pronunciation had taken place for the majority of students. The most important benefit gained as indicated by students was that the training helped correct their pronunciation of English. The second most important benefit students gained from pronunciation training was the ability to speak English more clearly. In addition, students felt that pronunciation classes had helped make them more conscious of their own pronunciation.

\section{Methodology}

\subsection{Subject}

The subject of this study included the students of Comilla Victoria Govt. College and Cantonment College in Comilla as well as Chittagong College in Chittagong, Bangladesh. The study took only the batch that completed $1^{\text {st }}$ year of higher secondary level. The total population of the study was 85 (eighty-five).

\subsection{Method of Sampling}

To collect data 3 colleges were selected for available students. Since the researcher intended to include the total population of the subjects, he tried to reach all the subjects. The population of the study was 85(Eighty-five), which were quite manageable for the researcher to include in the survey. For that reason, no other forms of sampling techniques were employed for extracting a representative sample of the population.

\subsection{Setting}

The data required for the study were collected from formal setting. Respondents were given questionnaires and they were interviewed in the formal classroom setting.

\subsection{Instruments}

The study primarily adopted quantitative method as a means of collecting and interpreting the data. However, qualitative method was also applied to some extent. A questionnaire comprising 14 questions was adapted from The Pronunciation Attitude Inventory (PAI), introduced by Elliot (1995). Item 1-6 were related to awareness of correct English pronunciation. The next items 7-14 related to attitude towards correct pronunciation were sought on 5-point scale which was calibrated as 'Never true', 'Usually not true', 'Somewhat true', 'Usually true', 'Always true'. All these questions were 
designed to collect the perception (positive or negative) of the students regarding correct English pronunciation.

\subsection{Procedure of Data Collection}

Data were collected in the form of questionnaire and interview. First of all, permissions were sought from three different colleges to fix an appointment. It took 2 weeks to collect data. After entering the classroom, the respective teacher gave instruction about the research survey. It was assured to the respondents that the information provided by the samples will be anonymous. It took on an average 510 minutes per student to conduct the survey. The questionnaires were administered to the students inside the classroom. Data were collected from a number of 85 subjects who were present in the class on the particular day. The subjects were provided the assurance that their identity would be kept secret and the responses would be used for research purpose only. There was no rigid time limit for the students to fill in the questionnaires; however it was suggested that they would not take more than thirty minutes. The students were provided with any kind of explanatory help for the understanding of the questions. The respondents were selected using point scale, ranging from 'Never true (1)' to 'Always true (5)'.Creating fear free environment, the students were interviewed and they were asked about some current mispronounced words.

\section{RESUltS AND DisCUSSION}

Pronunciation skills are very important specifically in spoken English. As mentioned by Fraser (2000a), “...with poor pronunciation, understanding a speaker will be difficult, despite accuracy in other areas." Therefore, the nonnative learners need to realize the importance as well as to have positive attitude toward acquiring them. The underlying philosophy of the listening and speaking course is to teach and learn pronunciation as an integral part of oral communication. The striking point is that it is artificial and counterproductive to divorce pronunciation from communication and other aspects of language use.

The following first items 1-6 are based on the discussion about awareness of correct English pronunciation of the respondents:

Item no. 1: "Do you know about Standard English pronunciation?" 21.18\% respondents responded 'Yes' and $78.82 \%$ respondents responded 'No'. The result shows that a very tiny number of participants know about Standard English pronunciation. On the other hand, a large number of participants do not know about standard pronunciation. This result shows that there is a great lack of awareness of correct English pronunciation among the higher secondary learners. Because the learners have neither learned nor heard about it. English is a compulsory subject at least at HSC level and almost all the students are very eager to pass in the examination. They think passing in English subject is a great achievement for them. Since there is little or no examination on Standard English pronunciation in the curriculum of Bangladesh. So, they do not bother about it. Their teacher might have never discussed about it. Therefore, the respondents think that they cannot speak normal English let alone Standard English. Although the respondents have been studying English for the last 12 years, they do not know about Standard English. Having a command of the standard pronunciation is a very important tool for a good communication in English. Saylor (2005) says that proper pronunciation means reproducing the sound of the word through speech in such a way that any fluent speaker of the language would effortlessly know and understand the message. Improper pronunciation causes a breakdown in communication and requires more effort to understand. The meaning between the words like effect and affect are easily confused if the pronunciation is not clear. Therefore, it goes without saying that the participants were not aware of learning standard English. There might be some reasons behind it such as the curriculum of Bangladesh, lack of awareness and sincerity of some teachers, lack of English-speaking environment and lack of awareness and enthusiasm of learners etc.

Item no. 2: "Do you practice correct pronunciation?" 8.24\% respondents responded 'Yes'. 91.76\% respondents responded 'No'. The findings show that almost all the respondents do not practice correct pronunciation. A very negligible number of respondents practice but a large number of respondents do not practice because they are not aware of it. Awareness of correct pronunciation practice is at the lowest level among the respondents. Although practice makes perfect, the respondents are not aware of gaining perfection in correct pronunciation through practice. English is a foreign language to the Bangladeshi people. Besides, there is no such environment to acquire the correct pronunciation 
naturally. Moreover, English language is notorious for its pronunciation. So, practice is a must to become skilled in pronunciation. But the respondents do not practice English pronunciation. Besides, to avoid miscommunication problems and embarrassing situations, pronunciation practice is essential and brings confidence to the EFL speakers. Practice discovers how sounds are articulated and pronounced in a very pleasant and stimulating way. However, the learners may not know that the practice focuses on micro-level and macro-level skills (Morley 1991). The micro- level training highlights discrete elements of pronunciation and voice (both segmental and suprasegmental features). Macro-level skills training features oral communication activities like role-play, group discussions, problem-solving tasks, speeches, and drama. Anyway, the result shows that the respondents are far away from practice of these activities. The most important thing for the learners to remember is the practice of correct English pronunciation. Learning correct pronunciation takes time but if one practices often one will soon improve and be able to pronounce words like a native speaker with fluency. What is more, it is true and over true in the context of Bangladesh that acquiring correct English pronunciation is not possible without practicing it.

Item no. 3: "Are you familiar with stresses in English words?" Around 7\% respondents responded 'Yes' and 93\% respondents responded 'No'. Here, we find that a very small number of respondents are aware of stresses in English words and more than 90\% respondents are not aware of stresses in English words. It is because the learners may not know that English is stress-timed but Bangla is syllable-timed language and stress is one of the most important elements in English pronunciation and sometimes it can change meaning of a word or a sentence. The learners may have heard about stresses to a little extent but they do not know the grave importance of stresses and their English teachers might have not emphasized it in the class. It is highly linked with speaking, listening and reading but it is very regretful that the respondents are not familiar with stresses in English. Their unawareness of stress clearly shows their lack of knowledge in pronunciation. In fact, experiments have demonstrated that often when a native speaker mishears a word; it is because the foreigner has put the stress in the wrong place, not because he or she mispronounced the sound of the word" (Joanne Kenworthy, 1987). Some students have a tendency to utter each syllable with equal length. It's often not so much a problem of making stressed syllables long enough, but of making unstressed ones short enough (Chela-Flores 2001:90). Therefore, the learners are in a great danger about stress placement of English.

Item no. 4: "Are you familiar with the IPA symbols?" Only 1\% respondent responded 'Yes', but 99\% respondents responded 'No'. Regarding this item almost 100\% students are not aware of IPA symbols which help students acquire correct English pronunciation. These IPA symbols are considered as the bases of correct pronunciation of each and every word in English. The respondents were not taught the IPA symbols in their 12- year- old education life. Learning the IPA symbols is the first step to know about correct pronunciation. As they do not know the IPA symbols so, correct pronunciation cannot be expected from them. The learners should have known that with the aim of minimizing the difference between spelling and sounds, the International Phonetic Alphabet (IPA) was developed in 1888 to provide a universal code that could represent the exact pronunciation of the sounds that exist in all languages. However, most EFL respondents of higher secondary level are not familiar with the IPA symbols, and even though the phonetic transcription is present in bilingual dictionaries, many respondents are unable to decode the symbols and end up feeling puzzled by the unsystematic way words are represented by orthography. It is important that the respondents themselves look for material that can help them overcome pronunciation difficulties. The IPA gives us a uniform international medium of studying and transcribing the sounds of all the languages of the world. As regards English, the respondents do not know that the IPA helps us in establishing and maintaining international intelligibility and uniformity in the pronunciation of English. With the help of the IPA symbols we can easily learn and teach the pronunciation of English or of any other languages. The learners should have known that the IPA has contributed a lot to the learning, teaching and description of language. The teachers and learners of English at higher secondary level can improve, and standardize their pronunciation and can overcome the confusion created by the spellings with the help of the International Phonetic Alphabet. But the learners do not know how to deal with the phonetic transcriptions used in the dictionaries. The teachers never teach the learners that they will find the standard pronunciation of each entry in the dictionary. Lee (2011) emphasizes that a useful strategy is to teach students to use English dictionaries and understand the phonetic transcription system used in dictionaries to represent pronunciation. This will not only build student awareness of the phonetic 
system of English, but also help them understand and visualize English syllable stress, another difficult aspect of pronunciation for some learners.

The learners intonate an English word through its phonetic transcription not through its spelling what would lead them to the mispronunciation. The more the learners learn the IPA, the better the learners pronounce the complicated words of English. Perhaps, one of the reasons for the students to have troubles with pronunciation is because there is not an appropriate study about the English sounds in courses in order to help them to learn more about correct English pronunciation.

Item no. 5: "Do you think you speak English in correct pronunciation?" $6 \%$ respondents responded 'Yes', but 94\% respondents responded 'No'. Here, a very few number of respondents think that they speak English correctly. But a large number of respondents do not think that they speak correctly. Therefore, it is clear that many respondents are not sure of their correct speaking in English. Naturally, a learner knows best about him/herself and this is why they do not think that they speak English in correct pronunciation. The respondents confess their weakness that is very sensitive in correct pronunciation. Setter and Jenkins (2005:6) in this regard mentions: "Pronunciation, it seems is a more sensitive area of language than other linguistic levels because of the way in which it encroaches on identity and elicits strong attitudes." The respondents have no confidence in their ability to speak correctly in English. This is a common scenario about correct English pronunciation at HSC level in Bangladesh. The main reason behind it is that neither the class teacher nor the learners are concerned with it though they know that at present no good English, no good job in home and abroad. (Graddol (2006: 22), in his study of global trends surrounding English, comments: 'On the one hand, the availability of English as a global language is accelerating globalization. On the other, the globalization is accelerating the use of English'. He refers to a statistical projection of the number of learners: '. . there could be around 2 billion people simultaneously learning English in the world's schools and colleges and as independent adults. Nearly a third of the world population will all be trying to learn English at the same time' (Graddol, 2006: 101). As the need intensifies for social, economic and technological communication at a global level, so English language should be taught and learned with correct pronunciation. But the present study shows a depressing picture of correct speech of the participants of higher secondary level in Bangladesh.

Item no. 6: "Do you think that you can find the correct pronunciation of a word by yourself (may be from a dictionary)?" $40 \%$ respondents responded 'Yes' and 60\% respondents responded 'No'. Here less than half of the respondents think that they can find correct pronunciation of a word by themselves from a dictionary. But more than half of the respondents do not think that they can find a word by themselves from a dictionary. Therefore, it is clear that the respondents' awareness is lower than unawareness of correct English pronunciation. $40 \%$ respondents think that they can find the correct pronunciation of a word from a dictionary but it is seen that almost hundred percent respondents do not know the IPA symbols. Even $60 \%$ respondents do not know that there are some dictionaries where they can find correct pronunciation. A large number of learners do not use the dictionaries in which English words are transcribed in IPA symbols because they do not know how to use such a dictionary. They are not taught how to look up a correct word in a dictionary. The current study shows that more than half of the respondents cannot recognize words with correct pronunciation and do not know how to look up correct pronunciation of a word in a dictionary.

The following discussion is based on the attitude of respondents about correct English pronunciation:

The item no. 7: "I'd like to sound as native as possible when speaking". Here, 'Never true' is $0 \%$, 'Usually not true' is $1.18 \%$, 'Somewhat true' is $3.53 \%$, 'Usually true' is $40 \%$, and 'Always true' is $55.29 \%$. The findings show that the respondents feel like speaking like the native speaker. They are very much interested to speak English fluently like the native speakers. It shows that the respondents will be happy if they can acquire the native accent. They wish to have a good command over native sound of the English speakers. The respondents have a good and very attitude to native speaking. This shows a great possibility to acquire the native sound spontaneously. This high attitude will pave the way of having a good command over correct and native sound.

The item no. 8: “Acquiring proper pronunciation is important to me". Here, 'Never true' is $0 \%$, 'Usually not true' is $1.18 \%$, 'Somewhat true' is $2.35 \%$, 'Usually true' is $17.65 \%$, and 'Always true' is $78.82 \%$. This shows the respondents belief that proper pronunciation is necessary for almost all of them. The respondents think that without proper pronunciation, they cannot speak correct English. 
They also do not think that they can speak properly without proper pronunciation. They want to give more emphasis on proper pronunciation and they do not support giving less importance to proper pronunciation. So, it is clear that they do not query about the importance of proper pronunciation. This high attitude is enough to propel the respondents to acquire proper pronunciation. The findings show that consciously or unconsciously the respondents feel the necessity of correct pronunciation. This high attitude towards importance of correct pronunciation may encourage gaining the knowledge of correct pronunciation to speak well.

The item no. 9: "I will never be able to speak English with a good accent". Here, 'Never true' is $58.82 \%$, 'Usually not true' is $31.76 \%$, 'Somewhat true' is $2.35 \%$, 'Usually true' is $5.88 \%$, and 'Always true' is $1.18 \%$. This means the respondents do not agree that they will never be able to speak English with a good accent. It shows the credence of their ability. The respondents think they have enough ability to speak with a good accent. The self-trust of the respondents exposes that they have the capability and they will progress immensely in speaking with good accent. The respondents are not afraid of this and they do not suffer from inferiority complex about their ability to speak English with a good accent. This attitude will quicken their progress in acquiring good accent.

The item no. 10: "I believe I can improve my pronunciation skills in English." Here, 'Never true' is $5.88 \%$, 'Usually not true' is $0 \%$, 'Somewhat true' is $2.35 \%$, 'Usually true' is $45.88 \%$, and 'Always true' is $45.88 \%$. This indicates that the respondents believe they can improve their pronunciation. Their attitude to improve English pronunciation is very positive. They think they can change themselves through the light of belief of improving pronunciation skills. Here, the attitude of the respondents is also very high and such high attitude is enough to make easy the way of improving pronunciation skills in English.

The item no.11: "I try to imitate English speakers as much as possible." Here,' Never true' is $5.88 \%$, 'Usually not true' is $10.59 \%$, 'Somewhat true' is $16.47 \%$, 'Usually true' is $32.94 \%$, and 'Always true' is $34.12 \%$. It shows a large number of respondents try to imitate English speakers as much as possible. This means a great attraction and interest are found among the respondents to imitate and acquire the skill in English pronunciation. They feel attracted by the native speakers of English. Their attitude is very positive and very high to speak like the native speakers.

The item no. 12: "Good pronunciation skills in English are not as important as learning vocabulary and grammar." Here, 'Never true' is $76.47 \%$, 'Usually not true' is $22.35 \%$, 'Somewhat true' is $1.18 \%$, 'Usually true' is $0 \%$, and 'Always true' is $0 \%$. This negative response further supports the findings of this study that the respondents have positive attitudes towards correct English pronunciation. They believe that even though they are fully equipped with extensive vocabulary and sound grammatical knowledge, pronunciation skills are still important aspects in order for them to be able to communicate with people efficiently. The respondents think that good pronunciation is as important as vocabulary and grammar. But vocabulary and grammar predominate over pronunciation in English in Bangladesh. The teacher and the learners are overwhelmed with teaching and learning English vocabulary and grammar. But the present study reveals that the learners think that there is an essential existence of pronunciation like vocabulary and grammar. If vocabulary is considered like concrete, grammar is like cement then pronunciation is the meaningful and beautiful distemper of the language. So, good pronunciation is essentially essential to the respondents. From the findings, it is revealed that the respondents believe to become the best speaker good pronunciation is very important in the national and international contexts.

The item no. 13: "I want to improve my accent when speaking English." Here, 'Never true' is 0\%, 'Usually not true' is $0 \%$, 'Somewhat true' is $14.12 \%$, 'Usually true' is $36.47 \%$, and 'Always true' is $49.41 \%$. The respondents' attitude is also high to this item. The respondents are enthusiastic to improve their accent while they speak. They are very positive, and enthusiastic to improve their accent practically. Therefore, it is needless to say that this high attitude will instigate the respondents to develop their accent when they speak English. This indomitable desire will lead them to the bucket of their improvement in the field of English accent.

The item no. 14: "Sounding like a native speaker is very important to me." Here, 'Never true' is $0 \%$, 'Usually not true' is $3.53 \%$, 'Somewhat true' is $10.59 \%$, 'Usually true' is $47.06 \%$, and 'Always true' is $38.82 \%$. It shows the very high positive attitude of the respondents to native sound. As the learners have studied English for many years, they think it is also important for them sounding like a native 
speaker. As English is a global language, so, the respondents think that native sound in English is important to them to be accepted globally. As the native sound is the authentic sound, that is why they desire to possess it. It is the Bangladeshi people who sacrificed their life for language. So, these Bangladeshi respondents are very sensitive to any aspect of language. This positive attitude will make the respondents active and they will attempt to acquire native sound as an important element of correct pronunciation.

\section{RECOMMENDATIONS AND CONCLUSION}

\subsection{Significance of the Findings}

The amazing findings from the present survey point out that the respondents have negligible awareness and at the same time they have excellent positive attitude to correct English pronunciation. The result reveals the lowest awareness which is the weakness and the highest attitude which is the strength of the participants. So, there is no point to be hopeless about correct English pronunciation of the higher secondary learners of Bangladesh. The interesting thing is that the strength of the highest attitude will be effective to overcome the weakness of the lowest awareness of the learners. What is more, prevention is better than cure. So, the diagnosis of the weakness of the participants can be used to prevent them from further incorrect English pronunciation. However, the higher secondary learners need to be aware to improve their skills in pronunciation. But they don't get much exposure from the classroom instructions which result in their ignorance of the importance of correct English pronunciation. On top of that, pronunciation is rare or unavailable in the English language curriculum in Bangladesh. Moreover, the English teachers are too burdened with syllabus to discuss correct pronunciation in English class. In addition to this, the large number of students and the short time of the class hinder the teacher to teach pronunciation in the class. In this regard Pillai (2008a: 42) opines that "the teaching of pronunciation is largely ignored, or gets side- lined as teachers scramble to deal with all the other elements in the English language syllabus and prepare students for examinations". Obviously, this present study proves what is being mentioned by Pillai (2008a) as the findings show a very low level of awareness of the respondents at higher secondary level regarding the importance of correct English pronunciation.

The present study also shows that correct English pronunciation is not practised in class which is the most appropriate platform to learn English pronunciation in the context of Bangladesh. So, English pronunciation instruction should be viewed in the same light as the other aspects and skills of the English language, such as vocabulary, grammar, reading and writing since it is an important part of communication. Correct pronunciation in English must be viewed as more than correct production of individual sounds or isolated words. It must be viewed as a vital part of communication that should be incorporated into classroom activities at least at higher secondary level of Bangladesh. Therefore, English pronunciation components have to be incorporated into the materials, classroom activities and testing tools at the higher secondary level; and the unaware teachers of correct pronunciation have to be trained in English pronunciation instruction.

\subsection{Recommendations}

Teachers can help students by highlighting elements such as sounds, syllables, stress and intonation in class. Teachers can actively encourage the students' actual production; build pronunciation awareness and practice in and outside the class. They can encourage them repeatedly to monitor their own pronunciation and practice their speaking skills as much as possible in and outside the classroom. Savignon (1997) stressed the need for meaningful communicative tasks in the language classroom, including those that focus on pronunciation. As English pronunciation is one of the most difficult parts for EFL learners to master and one of the least favorite topics for teachers to address in the EFL classroom, learners can do well in learning English pronunciation if the teacher and learner participate together in the total learning process. Cheng (1998) reported that teachers should choose meaningful materials to be used as models for practicing pronunciation aspects. With the teacher acting as a 'speech coach', rather than as a mere checker of pronunciation, the feedback given to the student can encourage learners to improve their pronunciation. If these criteria are met, all learners, within their unique aims, can be expected to do well learning the pronunciation of English language. Learners have to be careful listeners in their own conversations. Pitt (2009) shows that learners need exposure to conversations so that they can hear variation in pronunciation. Harmer (1993) stresses the need for making sure that students can always be understood and say what they want to say. In fact, they need 
to master good pronunciation, not perfect accents.

Since the participants express their desire to speak like the native speakers. A teacher can help overcome the psychological barrier and other challenges by helping students to sound like native speakers and helping them to learn the core elements of spoken language so that they can be easily understood by others. In other words, teachers and students can overcome the frustrations, difficulties, and boredom often associated with pronunciation by focusing their attention on the development of pronunciation that is listener-friendly. But some researchers argue that acquiring a native like pronunciation is impossible and even not required. Pennington (1989 cited in Maniruzzaman, 2008), however, does not take such belief into consideration saying that formal training on pronunciation can make a difference. Ur (1999:55) also supports the idea saying "there is also evidence that deliberate correction and training does improve pronunciation and if this is so, it seems pity who neglect it" However, it is true that we cannot master some aspects of English pronunciation when it comes to suprasegmentals, for example pitch movement (Walker, 2001). But we cannot forget that many aspects of English pronunciation, especially segmental, are learnable. Thus it can be said that we need pronunciation for mutual intelligibility at the global level today.

The findings also reveal the ignorance of the participants about Standard English pronunciation. In the EFL teaching learning scenario of Bangladesh, the traditional concept of standard accent in English pronunciation that is of the native speakers', still dominates unsurprisingly. Here, the language English enjoys distinctive prestige and high status among not only the common people but also among most of the learners and the teachers. Fluent speaker or competent user of English is well accepted as someone smart, knowledgeable and respectable. The findings light up that native like pronunciation is the much aimed norm by the learners and teachers without any question. Even any deviation in standard pronunciation of native accent is strongly considered inferior and therefore not valued. Many FL/L2 learners of English in Bangladesh, who are commonly found with inadequate minimum English grammatical or communicative competence, usually get the tendency to ensure that they are taught the British or American accent in their English pronunciation. Often they rank their English teachers on the nativeness of the teachers in their pronunciation. Accordingly, the English teachers usually discover themselves pressurized to obtain and maintain British or American accent in their English accent and pronunciation for achieving professional success. So, in the field of awareness and attitude to English language teaching-learning, the traditional conservative trend of acquiring as close as possible to the native standard pronunciation continues without any question. There should not be any further delay to address this issue in the present context of English language teaching and learning in Bangladesh. In this way, in a country like ours, the accurate objective in increasing awareness of correct English pronunciation can be redefined and set with proper step

\subsection{The Gist of Some Fruitful Tips to Make Aware the Higher Secondary Learners of Bangladesh}

- Including the syllabus of correct pronunciation in the national curriculum at HSC level in Bangladesh.

- Setting question in the public examinations about correct English pronunciation at least at SSC and HSC levels.

- Providing a list of hugely mispronounced words along with correct pronunciation in English books of National Curriculum and Text Book (NCTB).

- Teachers should be made aware of correct pronunciation through training before making aware of the students.

- Emphasizing the importance of correct pronunciation in the English class by English teachers and trainers.

- Arranging seminar on correct English pronunciation by the language experts of home and abroad.

- Giving instructions on English pronunciation by the language experts through media such as newspaper, television, radio, social media and so on.

- Arranging sometimes correct pronunciation competition on different channels of Bangladesh.

- Organizing a team of language experts to pay a visit to higher secondary level of Bangladesh to make aware of English pronunciation. 
- Informing the learners of bad effects of wrong pronunciation and the soul stirring benefits of correct pronunciation.

- Asking sometimes the students some most commonly mispronounced words prevalent in Bangladesh such as front, bald, basic, nature, onion, different, listen, prefer, enthusiasm, grandfather, handsome, quay, adjective, sew, opportunity, April, political, azure, rumour, drought, malign, malignity, consumer, August, assume, ship, sheep, extraordinary, Wednesday, zero, hero, etc.

- Discussing different types of accents to make the learners aware. There are many different kinds of English accents. The two most common are British or American pronunciation, but most learning materials will help students learn either a standard British accent or a standard American accent.

- Recording their speech. It is important to hear what students sound like while speaking English so that they know what they need to improve. They can compare what they sound like to what they want to sound like. For example, they record themselves reading a sentence from an audio source. Then, they will listen to the record and compare their pronunciation.

- Using and keeping good pronunciation books in college library so that students may collect those books and become conscious of correct pronunciation.

\subsection{Concluding Remark}

Although the awareness of the respondents is very shockingly low, the amazing attitude of the respondents can change the present situation of unawareness of correct English pronunciation at the higher secondary level in Bangladesh. The ray of hope may be seen by removing the black glass from awareness of correct English pronunciation at the higher secondary level in Bangladesh through the appreciable attitude of the respondents.

Finally, the learners should attempt to implement their indomitable attitude which is enough to open all the doors for acquiring correct English pronunciation in no time at higher secondary level in Bangladesh. No doubt, the surge of the highest attitude will replace the lowest awareness of higher secondary learners for correct, rapid and error-free English pronunciation in Bangladesh.

\section{REFERENCES}

[1] Cook, V. Second Language Learning and Language Teaching. London: Arnold. (1996).

[2] Crystal, D. English as a Global Language (Second ed.). Cambridge: Cambridge University Press. (2003).

[3] Nusrat Jahan "Teaching and Learning Pronunciation in ESL/EFL Classes of Bangladesh" Journal of Education and Practice. ISSN 2222-1735 (Paper) ISSN 2222-288X (Online) Vol. 2, No 336, (2011).

[4] Elliot, R.A. Foreign language phonology: Field independence, and the success of formal instruction in Spanish pronunciation. Modern Language Journal, 79(4), 530- 542. (1995).

[5] Sparks, R. \& Ganschow, L. Foreign language learning differences : Affective or native language aptitude difference? The Modern Language Journal, 75 (1), pp.3- 16. (1991).

[6] Rajadurai, J.. An Investigation of the Effectiveness of Teaching Pronunciation to Malaysian TESOL Students. Forum, 39(3), 10-15. (2001).

[7] Fraser, H.Coordinating Improvements in Pronunciation Teaching for Adult learners of English as a Second Language. Canberra: DETYA (Australia National Training Authority Adult Literacy Project). (2000).

[8] Saylor, Stephen. Importance of English pronunciation. (2005).

[9] Kenworthy, J. Teaching English pronunciation. Harlow, U.K.: Longman. (1987).

[10] Chela-Flores, Bertha. 'Pronunciation and language learning: An integrative approach. (2001).

[11] LEE, Felicia. Phonics to improve English pronunciation. (2011).

[12] Setter \& Jenkins. Pronunciation. State-of-the Art Article. Language Teaching: 38:1. (2005).

[13] Graddol, D.: The Future of English? The British Council: London. . (2006).

[14] Pillai, S. Speaking English the Malaysian way - correct or not? English Today 96(24/4), 42-45, (2008a).

[15] Savignon, S. Communicative competence: Theory and classroom practice. New York: McGraw-Hill. (1997).

[16] Cheng, F. The teaching of pronunciation to Chinese students of English. English Teaching Forum, Jan Mar, 37-39. (1998). 
[17] Pitt, M. How are pronunciation variants of spoken words recognized? A test of generalization to newly learned words. Journal of Memory and Language, 61(1), 19-36. Pronunciation: A Reference for Teachers of English to Speakers of Other Languages. (2009).

[18] Harmer, J. The practice of English language teaching. New York, NY: Longman. . (1993).

[19] Pennington, M., and J. Richards.. Pronunciation revisited. TESOL Quarterly, 20, 2, pp. 207-225. (1986).

[20] Ur, P. A Course in Language Teaching. Cambridge: CUP, (1999).

[21] Walker, R. Pronunciation for International Intelligibility, IATEFL PronSIG, Issue 21:4-10, (October, 2001).

\section{AUTHORS' BIOGRAPHY}

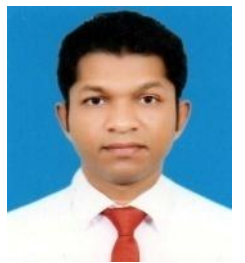

Mr. Md. Khurshedul Alam as a Lecturer in English, he has been teaching English language to the undergraduate students in the Faculty of Science at University of Chittagong, Bangladesh since 2018. He obtained his BA (Honours) in English in 2013 and MA in Applied Linguistics \& ELT in 2015 from Comilla University, Bangladesh. He was the Senior Lecturer and Head of the English Department of Cox's Bazar International University for around two and a half years and at the same time he was also the Coordinator as well as Trainer of English Language Institute of that university. Since then he has also been serving as the Coordinator of "Book Reading Competition" of British Council. Teaching English language is his first and last mission of his life.

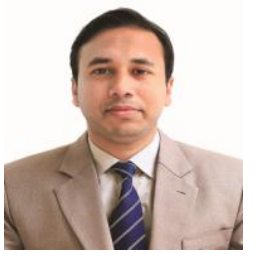

Mr. K.M. Jubair Uddin, a Lecturer in English, has been serving at the faculty of Biological Sciences in the University of Chittagong, Bangladesh. Formerly, he worked for Cantonment English School \& College as a Lecturer in English for almost 5 years. In addition to his assigned job ,he used to teach English language to junior teachers and army personnel from time to time. This has been almost one year since he joined the faculty of Biological Sciences as a faculty member in the University of Chittagong. He got admitted to the University of Chittagong in 2005 in the course of English Language and Literature and completed his graduation in 2009 and took his M.A Degree in 2010 respectively. Now he teaches English to the undergrad students of the different departments of Faculty of Biological Sciences

Citation: Md. Khurshedul Alam, K.M. Jubair Uddin. "Awareness and Attitude to Correct English Pronunciation at Higher Secondary Level in Bangladesh" International Journal on Studies in English Language and Literature (IJSELL), vol 7, no. 3, 2019, pp. 30-40. doi: http://dx.doi.org/10.20431/ 23473134.0703005.

Copyright: () 2019 Authors. This is an open-access article distributed under the terms of the Creative Commons Attribution License, which permits unrestricted use, distribution, and reproduction in any medium, provided the original author and source are credited. 